\title{
Cognitive Emotion Regulation Strategies and Cognitive Flexibility Levels in High School Students Subjected to Peer Bullying
}

\author{
๑ Behiye Sumeyra Bilgic, ๑ Arzu Onal Sonmez*, • Ayten Erdogan** \\ Green Crescent Consultancy Center, Istanbul, Turkey \\ *University of Health Sciences Turkey, Sariyer Hamidiye Etfal Training and Research Hospital, Clinic of Child and Adolescent Psychiatry, \\ Istabul, Turkey \\ **Istanbul Gelisim University Institute of Social Sciences, Department of Child and Adolescent Psychiatry, Istabul, Turkey
}

\section{Abstract}

\begin{abstract}
Aim: Peer bullying is thought to be negatively affected by high school students in many respects such as cognitive, emotional, psychological and physical. It is aimed to examine the relationship between cognitive flexibility levels and cognitive emotion regulation strategies of high school students who were exposed to peer bullying. Furthermore, it is examined whether these variables differ according to sociodemographic differences.
\end{abstract}

Methods: The sample of the study consists of 400 high school students reached via the internet from different cities of Turkey in 2020. The data in the study were obtained using "the peer bullying scale", "cognitive flexibility scale", "cognitive emotion regulation scale" and "sociodemographic information form" prepared by the researcher.

Results: It was found statistically significant that boys were subjected to more bullying on the peer bullying scale in the subscales of terror, teasing, and open attack. The rates of bullying students in vocational and technical high schools, who had poor school success and friendship relationships, were also found to be statistically significant $(p<0.005)$. Students with good school achievement and friendship relationships had higher levels of cognitive flexibility, while boy students and those with very good friendship relationships scored highly on the "refocusing on planning" subscale of the cognitive emotion regulation scale $(p<0.05)$.

Conclusion: According to our research, cognitive flexibility decreases as peer bullying levels increase. The use of maladaptive cognitive emotion regulation strategies also appear to increase.

Keywords: Bullying, cognition, flexibility, emotion regulation

\section{Introduction}

Peer bullying negatively affects children's cognitive, emotional, psychological, and physical development in many factors. Children's bullying behavior affects not only their developmental processes but also their school and daily life, emotional and behavioral processes. In recent years, it is seen that research on peer bullying, which is common both in our country and in other countries, has increased.

Exposure to peer bullying has an impact on cognitive coping skills and emotional arrangements. Cognitive flexibility is defined as the awareness of alternative ways and options to adapt to a situation (1). Problemsolving involves the process of finding solutions to problems encountered when heading towards a goal (2). Accordingly, problem-solving skills and cognitive flexibility are parallel in looking for alternative solutions to problems (2-4).

Emotion regulation consists of internal and external processes used to monitor, evaluate and alter a person's emotional responses, which are particularly intense and transient for the person in achieving their goals (4-6). Cognitive emotion regulation is the cognitive way to express the cognitive part of coping skills and manage

Address for Correspondence: Arzu Onal Sonmez, University of Health Sciences Turkey, Sariyer

Hamidiye Etfal Training and Research Hospital, Clinic of Child and Adolescent Psychiatry, Istabul, Turkey E-mail: arzudr@yahoo.com ORCID: orcid.org/0000-0001-7370-9211

Received: 10.10.2021 Accepted: 19.10.201

'Copyright 2021 by The Medical Bulletin of istanbul Haseki Training and Research Hospital The Medical Bulletin of Haseki published by Galenos Yayınevi. 
emotionally stimulating information intake. Emotional and behavioral responses caused by peer bullying may be associated with children's cognitive flexibility levels and emotion editing methods, thus adversely affecting their cognitive flexibility and cognitive emotion regulation strategies (7).

In this study, we aimed to the level of peer bullying in high school students, the cognitive flexibility levels, and cognitive emotion regulation strategies of peer bullying, based on the assumption that high school freshmen and sophomore students who are trying to adapt to a new environment and school environment may be more affected.

\section{Methods}

\section{Study Design}

The present study was approved by Istanbul Gelisim University Ethics Committee (date: 12.03.2020, number: 2020-07). In this study, 400 students between the ages of 14 and 16 who attended high school one and high school sophomore education in different cities of Turkey were included. The cases consist of high school students reached via the internet from different cities of Turkey in 2020. "peer bullying scale", "cognitive flexibility scale", "cognitive emotion regulation scale" and "sociodemographic information form" were used. Exclusion criteria were psychiatric diseases and neurological diseases and cases with poor course success. The scales were filled by mutual interviews by the psychologist via the Internet. Informed consent forms of children and families were obtained via e-mail.

\section{Sociodemographic Information Form}

It consists of questions prepared by the researcher to obtain the demographic information of the students. At the beginning of the form, there is informed consent that introduces the research and includes approval for voluntary participation.

\section{Peer Bullying Scale}

The peer bullying scale (PBS) used in the study was adapted to Turkish by Gültekin and Sayil (8) based on the scale developed by Mynard and Joseph (9) to determine the exposure of school children to peer bullying and was developed as a suitable scale for Turkish children and adolescents (10).

The original scale is of the type of self-notification and can be applied individually or in groups. Students who participate are asked to choose "never", "once" and "more than one" for each item on the scale. The selected options are scored by giving 2 for "more than", 1 for "once" and 0 for "never". There are 16 items on the original scale, and the highest score from the scale in total is 32 and the lowest score is 0 . As scores from the scale rise, the frequency of peer bullying increases, and as scores drop, it is rarely thought that they are bullied or not exposed at all. As a result of the analysis of the basic components applied to the data on the original scale, the substances were collected in 4 factors specified as physical, verbal, social, and psychological bullying. The scale of Gultekin and Sayil (8) consists of 27 items as a result of the development work and analysis for Turkish children and adolescents. As a result of the factor analysis carried out on the scale, 5 factors defined as error, overt victimization, teasing, relational victimization, and attacks on property were obtained.

\section{Cognitive Flexibility Scale}

The cognitive flexibility scale (CFS) was developed by the Scholar to measure adolescents' cognitive flexibility (11). This scale allows us to understand how flexible individuals are to themselves, others, and their environment. The scale is a scale of semantic differences and consists of 19 items. Scaled scoring is calculated by giving a score of "5-4-3-2-1" from positive to negative (e.g. I Can't Succeed). As the scores are increasing, the level of cognitive flexibility increases.

\section{Cognitive Emotion Regulation Scale}

The cognitive emotion regulation scale (CER) was developed by Garnefski et al. (12) to measure the cognitive emotion regulation strategies people use against stressful and threatening life events and was adapted to Turkish by Ataman (13) and validity and reliability studies were carried out. It consists of 36 items and nine subscales on a scale. Each of the subscales has 4 items. CER is a scale selfdeclaration type that can be applied to people 12 years and older. The substances are of type 5 lichen and are evaluated between 1 (none) to 5 (always). The score of each of the subscales ranges from 4 to 20 and is evaluated with ratings from the subscales. It is understood that the higher the score from the subscale, the more the strategy indicated by that subscale is used $(12,14)$.

\section{Statistical Analysis}

The data obtained were entered into the computer environment as a numerical expression and statistical analysis was carried out using the statistical package program (SPSS 25.0) for social sciences. Before starting the analysis, the data were examined in terms of normal distribution. In small samples $(n<30)$, the KolmogorovSmirnov test was used because the Shapiro-Wilk test produced stronger results in detecting normal nondispersing conditions, and in large samples $(n>30)$ it produced the best results for deciding by avoiding type I errors. A p-value of 0.05 or less was considered statistically significant. 


\section{Results}

The study consisted of 114 (28.5\%) boys and 286 (71.5\%) girls attending the first year of high school one and sophomore year (Table 1).

Nine percent of the sample was found to be subjected to peer bullying, $7.5 \%$ to terror, $15.3 \%$ to tease, $13.3 \%$ to overt victimization, $14.5 \%$ to relational victimization, and $8.3 \%$ to attacks on property (Table 2 ).

The PBS and relational victimization, attack on property scores on the item do not differ significantly by gender variable $(p>0.05)$. There was a statistically significant difference in the subscale of terror, teasing, open attack compared to girls $(p<0.05)$ (Table 3$)$.

When differences in CFS and subscales were examined by school type, students in Vocational and Technical High Schools scored higher than students in other high schools $(p<0.005)$ (Table 4).

There is a moderate negative correlation between the PBS and CFS score $(r=-0.315 p<0.01)$. Terror $(r=-0.122$ $p<0.01)$, tease $(r=-0.098 p<0.01)$, open victimization $(r=-$ $0.176 p<0.01)$, relational attack $(r=-0.264 p<0.01)$, attack on property $(r=-0.122 p<0.01)$ and CFS score found to be negatively weak. Refocusing on plan subscale scores differ

\begin{tabular}{|c|c|c|}
\hline & & n (\%) \\
\hline \multirow{3}{*}{ Sex } & Boy & $114(28.5 \%)$ \\
\hline & Girl & $286(71.5 \%)$ \\
\hline & Total & $400(100 \%)$ \\
\hline \multirow{2}{*}{ Class } & $9^{\text {th }}$ grade & $223(55.8 \%)$ \\
\hline & $10^{\text {th }}$ grade & $177(44.2 \%)$ \\
\hline \multirow{4}{*}{ School type } & Anatolian & $180(45 \%)$ \\
\hline & & $101(25.3 \%)$ \\
\hline & Vocational and Technical & $91(22.8 \%)$ \\
\hline & Science & $28(7 \%)$ \\
\hline \multirow{4}{*}{ Success at school } & Poor & $27(6.8 \%)$ \\
\hline & Middle & $188(47 \%)$ \\
\hline & Good & $157(39.3 \%)$ \\
\hline & Very good & $28(7 \%)$ \\
\hline \multirow{4}{*}{$\begin{array}{l}\text { Friendship } \\
\text { relations }\end{array}$} & Poor & $15(3.8 \%)$ \\
\hline & Middle & $66(16.5 \%)$ \\
\hline & Good & $164(41 \%)$ \\
\hline & Very good & $155(38.8 \%)$ \\
\hline \multirow{2}{*}{$\begin{array}{l}\text { Parental marital } \\
\text { status }\end{array}$} & Married & $367(91.8 \%)$ \\
\hline & Divorced & $33(8.3 \%)$ \\
\hline \multirow{2}{*}{$\begin{array}{l}\text { Education status- } \\
\text { mother }\end{array}$} & Elementary school graduate & $189(47.3 \%)$ \\
\hline & Middle school graduate & $84(21 \%)$ \\
\hline
\end{tabular}

significantly by gender variable $(p<0.05)$. There was a positively weak relationship between self-blame $(r=0.208$, $p<0.01)$, rumination $(r=0.249, p<0.01)$, putting into perspective $(r=0.114, p<0.01)$, catastrophing $(r=0.164$ $p<0.01)$, and other-blame $(r=0.215, p<0.01)$ and the PBS score (Table 5).

\section{Discussion}

In this study, high school students' exposure to peer bullying and their cognitive flexibility levels, cognitive emotion regulation strategies and their relationship were investigated. Olweus also conducted a large sample in Norway, which found that $15 \%$ of students (aged 7 to 16) experienced bullying and victimization, $9 \%$ were victims of bullying and $7 \%$ were those who were bullying others (15). In this study, peer bullying was found to be $9 \%$. Another study in the United States found that the prevalence of being a victim of peer bullying or bullying at school at least once in the last two months was $20.8 \%$ physically, $53.6 \%$ verbally, $51.4 \%$ relationally, and cyberbullying $13.6 \%$ (16). A study of high school students in Turkey found that all students were bullied at least once during their student life, of which $33.5 \%$ were verbal, $35.5 \%$ physical, $28.3 \%$ psychological, and $15.6 \%$ sexual assault (17).

In our study, it was determined that the most common exposure in terms of bullying was teasing, relational

\begin{tabular}{|l|l|}
\hline \multicolumn{2}{|l|}{ Table 2. Distribution of sample group by peer bullying cutting } \\
\hline score & n (\%) \\
\hline Group not subjected to peer bullying & $364 \%(91)$ \\
\hline Peer bullying group & $36 \%(9)$ \\
\hline Group not subjected to terror & $370 \%(92.5)$ \\
\hline Group subjected to terror & $30 \%(7.5)$ \\
\hline Group not subjected to teasing & $339 \%(84.8)$ \\
\hline Group subjected to teasing & $61 \%(15.3)$ \\
\hline Group not exposed to overt victimization & $347 \%(86.8)$ \\
\hline Overt victimization group & $53 \%(13.3)$ \\
\hline Group not subjected to relational victimization & $342 \%(85.5)$ \\
\hline Group subjected to relational victimization & $58 \%(14.5)$ \\
\hline Group not attacks on property & $367 \%(91.8)$ \\
\hline Group attacks on property & $33 \%(8.3)$ \\
\hline $\begin{array}{l}\text { 9.3\% of the sample was found to be subjected to peer bullying, 7.5\% to terror, } \\
\text { and } 8.3 \% \text { to attacks on property }\end{array}$ & \\
\hline
\end{tabular}


Bilgic et al. Cognitive Emotions and Flexibility Levels

\begin{tabular}{|c|c|c|c|c|c|c|c|}
\hline & & $N$ & s.o & K.T & $\mathbf{U}$ & z & $p$ \\
\hline Peer Bullying & Boy & 114 & 212.35 & 24207.50 & 14951.50 & -1.311 & 0.190 \\
\hline \multirow{2}{*}{ Scale } & Girl & 286 & 195.78 & 55992.50 & - & - & - \\
\hline & Total & 400 & - & - & - & - & - \\
\hline \multirow{2}{*}{ Terror } & Boy & 114 & 221.47 & 25247.50 & 13911.50 & -3.715 & $0.000 *$ \\
\hline & Girl & 286 & 192.14 & 54952.50 & - & - & - \\
\hline \multirow{2}{*}{ Tease } & Boy & 114 & 217.78 & 24826.50 & 14332.50 & -2.026 & $0.043 *$ \\
\hline & Girl & 286 & 193.61 & 55373.50 & - & - & - \\
\hline \multirow{2}{*}{ Overt Vict. } & Boy & 114 & 230.04 & 26224.00 & 12935.00 & -3.741 & 0.000 * \\
\hline & Girl & 286 & 188.73 & 53976.00 & - & - & - \\
\hline \multirow{2}{*}{ Relational Vict. } & Boy & 114 & 195.06 & 22237.00 & 15682.00 & -0.650 & 0.516 \\
\hline & Girl & 286 & 202.67 & 57963.00 & - & - & - \\
\hline \multirow{2}{*}{ Attac. on prop } & Boy & 114 & 211.09 & 24064.00 & 15095.00 & -1.390 & 0.165 \\
\hline & Girl & 286 & 196.28 & 56136.00 & - & - & - \\
\hline
\end{tabular}

\begin{tabular}{|c|c|c|c|c|c|}
\hline & N & 5.0 & $x^{2}$ & SD & p \\
\hline CFS Anatol. HS & 180 & 216.19 & 13.608 & 3 & $0.226^{*}$ \\
\hline Anatol.Imam Hatip HS & 101 & 191.00 & - & - & - \\
\hline $\begin{array}{l}\text { Vocational and Technical } \\
\text { HS }\end{array}$ & 91 & 168.82 & - & - & - \\
\hline Science HS & 28 & 236.86 & - & - & - \\
\hline
\end{tabular}

victimization, open victimization, attacks on property, and terror respectively. A study (18) with high school students also found that the most common form of bullying was "teasing" followed by terror, relational victimization, open victimization, and attacks on property, respectively. In our study boys are bullied more in the subscales of terror, teasing, and overt victimization. Consistently with our findings (19) boys were more likely to be bullied by peers than girls. Consistent with these findings, studies in the literature show that boys are more involved in physical and verbal bullying and girls are more involved in relational bullying and girls exhibit bullying behaviors such as teasing and relational victimization more often than boys rather than physical bullying $(16,20)$.

Students with poor school achievement were found to be more bullied than those with good school achievement (21). It is thought that poor school achievement of students may be a factor in being subjected to peer bullying.

In terms of friendship relations, we found that students with good friendships are less bullied. Poor friendship relations increase the rate of peer bullying, and good friendship relation is a protective factor in terms of bullying. Consistent with the findings of this research in the literature, victims report that they have failed to relate to their peers in particular and have established fewer social relationships. As a result of these studies, those who are bullied are socially isolated and have poorer social skills. Social isolation of those who are bullied is often both the result and the cause of victimization (20). Bullying has recently been conceptualized as a relationship problem, suggesting that this aggressive behavior occurs in the context of a relationship between peers (22).

There are significant differences in cognitive flexibility according to the type of high school, which may be explained by factors such as the socioeconomic level of students, their academic achievements, the physical and social conditions of schools, and the provision of adequate support in and out of school-related to compliance (23). As school success increases, so does the level of cognitive flexibility (24).

In the subscale of "refocusing on the plan", it was found that boys used the strategy of regulating this feeling against stress and negative situations more often than girls (25). In the literature, boys are more used to the "otherblame" strategy of cognitive emotion regulation than girls (26). Other studies concluded that (27) the biggest differences between boys and girls were in using "putting into perspective", "rumination" and "other-blame" strategies. Girls used the "rumination" and "putting into perspective" strategies more often when faced with a stressful event, while boy concluded that they used the "other-blame" strategy more often. 


\begin{tabular}{|c|c|c|c|c|c|c|}
\hline & PBS & Terror & Tease & OV & RV & AOP \\
\hline Self-blame & 0.208 & $0.112^{*}$ & $0.209^{* *}$ & 0.167 & 0.160 & 0.141 \\
\hline Acceptance & -0.216 & & $-0.195^{\star *}$ & $0-.192$ & -0.161 & $-0.121^{*}$ \\
\hline Rumination & 0.249 & 0.072 & $0.229 * \star$ & $0.169^{\prime \prime}$ & 0.232 ** & $0.125^{\star}$ \\
\hline Planning & 0.033 & 0.005 & 0.029 & 0.078 & 0.012 & 0.045 \\
\hline Positive refocus. Positive refocusing & 0.056 & 0.029 & 0.057 & 0.078 & 0.055 & 0.069 \\
\hline Putting into pers. & $0.114^{*}$ & 0.011 & $0.099 *$ & $0.115^{*}$ & $0.105^{*}$ & $0.116^{*}$ \\
\hline Catastrophe & 0.164 & 0.085 & 0.153 & 0.137 & 0.140 & 0.149 \\
\hline Other-blame & 0.215 & 0.065 & 0.162 & 0.146 & $0.232^{* *}$ & 0.090 \\
\hline
\end{tabular}

Students in Vocational and Technical High Schools use the subscales of "self-blame" and "Catastrophe" more than students in other high schools. It turns out that students in Vocational and Technical High Schools are more inclined to use "Self-blame" and "Catastrophe" strategies from cognitive emotion regulation strategies when faced with negative, threatening events. A study of 9-11-year-olds in the literature (28) found significant differences in the subscales of self-blame, positive reappraisal, rumination, positive refocusing, and planning from cognitive emotion regulation strategies in favor of private school students.

When the relationship between PBS and CFS is examined, it shows that the level of cognitive flexibility decreases as peer bullying exposure increases. As PBS subscales such as "Intimidation/Intimidation", "tease", "overt victimization", "relational victimization" and "attacks on property" increase, exposure to peer bullying appears to reduce cognitive flexibility (29). From this point of view, as the level of cognitive flexibility increases, social abilities develop, and happiness level increases (30).

When the subscales of the CER scale with PBS are examined; As cognitive emotion-regulation strategies such as "self-blame", "putting into perspective", "rumination", "other-blame" and "Catastrophe" increase, so do the types of bullying such as "terror", "tease", "overt victimization", "relational victimization" and "attacks on property". Cognitive maladaptive coping strategies increase as bullying increases. In studies with adolescents found that the choice of cognitive emotion-regulation strategies played a partial agent variable role on cognitive flexibility and emotional autonomy $(31,32)$. It was also observed that the level of use of the "acceptance" cognitive emotion regulation strategy decreased as the exposure to bullying increased. Acceptance and positive refocusing from cognitive emotion-regulating strategies reduce depression (33); terror and rumination strategies have been shown to explain the increase in anxiety and the acceptance strategy explains the decrease in the level of anxiety (34).

Cognitive flexibility decreases as "self-blame", "rumination", "catastrophe" and "other-blame" strategies are used (35). It can also be interpreted that the more cognitive flexibility increases, the more likely it will be to use the "acceptance" strategy. In a study that investigated the effect of cognitive flexibility on cognitive emotion regulation; As the level of "alternative" subscale, which is expressed on the CFS as "measuring the ability to perceive that there are alternatives to situations encountered in life and one's behavior, and the ability to produce solutions to difficult situations", increases, so does the level of using "other-blame", "catastrophic", "positive refocusing", "refocusing on planning" and "positive reappraisal" strategies from cognitive emotion regulation (36-38).

\section{Study Limitations}

One of the limitations of our study is that our research is carried out with scales filled over the internet. Taking the sample from across the country increases diversity but impairs homogeneity. The high number of cases and the filling of scales with the psychologist are the strengths of our study.

\section{Conclusion}

It was observed that students' cognitive flexibility levels decreased as peer bullying exposure increased and they preferred to use maladaptive cognitive emotion regulation strategies. With the prevention of peer bullying, it is thought that students can use harmonious cognitive emotion regulation strategies by developing alternative 
methods to be more flexible and adaptable in the face of the situations they encounter.

*This study was produced from the first author's master's thesis.

\section{Authorship Contributions}

Concept: B.S.B., A.E., Design: B.S.B., A.E., Data Collection or Processing: A.O.S., Analysis or Interpretation: A.O.S., Literature Search: B.S.B., A.E., Writing: B.S.B., A.E.

Conflict of Interest: No conflict of interest was declared by the authors.

Financial Disclosure: The authors declared that this study received no financial support.

\section{References}

1. Mahmoudi Souran $H$, Sanagouyemoharer GR, Shirazi M. Acceptance and Commitment Therapy Improves Psychological Flexibility of Students with Thalassemia Major: A Randomized Controlled Trial. Practice in Clin Psychol 2019;7:107-16.

2. Bilgin M. Some variables predicting cognitive flexibility. Çukurova Üniv. Eğ Fak Derg 2009;3:142-57.

3. Waltmann M, Schlagenhauf F, Deserno L. Retest-Reliability of the Cognitive Flexibility Metrics of a Probabilistic Reversal Learning Task. Psychiatry Biol 2021;89:S130-1.

4. Thompson RA. Emotion dysregulation: A theme in search of definition. Dev Psychopathol 2019;31:805-15.

5. Thompson RA. Emotion regulation: a theme in search of definition. Monogr Soc Res Child Dev 1994;59:25-52.

6. Capps S, Foster R. Association of Child Emotion Understanding and Emotion-Related Behavior during a Delay of Gratification Task 2019.

7. Li L, Chen X, Li H. Bullying victimization, school belonging, academic engagement and achievement in adolescents in rural China: A serial mediation model. Children and youth services review 2020;113:1-8.

8. Gültekin Z, Sayil M. Developing the scale of determining peer bullying . Turk Psychol Articl 2005;8:47-61.

9. Mynard H, Joseph S. Development of the multidimensional peer-victimization scale. Aggressive Behavior: Aggress Behav. 2000;26:169-78.

10. Bilgin M. Developing a cognitive flexibility scale: Validity and reliability studies. Soc Behav Pers 2009;37:343-54.

11. Buelga S, Martínez-Ferrer B, Cava M-J, Ortega-Barón J. Psychometric properties of the CYBVICS cyber-victimization scale and its relationship with psychosocial variables. Soc Sci 2019;8:13.

12. Garnefski N, Kraaij V, Spinhoven P. Manual for the use of the Cognitive Emotion Regulation Questionnaire. Leiderdorp, The Netherlands: DATEC. 2002.

13. Ataman $\mathrm{E}$. The role of cognitive emotion regulation strategies in determining the level of depression and anxiety in the face of stressful life events. Unpublished Master's Thesis, Hacettepe University, Ankara. 2011.

14. Garnefski N, Kraaij V. Cognitive emotion regulation questionnaire-development of a short 18-item version (CERQshort). Pers Individ Differ 2006;41:1045-53.

15. Olweus D. Bullying at school. Basic facts and an effective intervention programme. Promot Educ 1994;1:27-31, 48.

16. Wang J, lannotti RJ, Nansel TR. School bullying among adolescents in the United States: physical, verbal, relational, and cyber. J Adolesc Health 2009;45:368-75.

17. Kepenekci YK, Cinkir S. Bullying among Turkish high school students. Child Abuse Negl 2006;30:193-204.

18. Kavşut F. Examination of the relationship between peer bullying and emotional intelligence in adolescents. Unpublished master's thesis) Abant İzet Baysal University/ Institute of Social Sciences, Bolu. 2009.

19. Erbiçer ES. Examination of Cyber Bullying and Cyber Victimizarion According to Social Adjustment and Certain Demographic Variables. Pamukkale J Facult Educ 2019:1-24.

20. Craig WM, Pepler DJ. Identifying and targeting risk for involvement in bullying and victimization. Can J Psychiat 2003;48:577-82.

21. Yuile A, Pepler D, Craig W, Connolly J. 5. The Ethics of Peeking behind the Fence: Issues Related to Studying Children's Aggression and Victimization. Ethical issues in community-based research with children and youth: University of Toronto Press, 2016, pp. 70-90. https://doi. org/10.3138/9781442674653-008.

22. Demanet J, Van Houtte M. The impact of bullying and victimization on students' relationships. Am J Health Educ 2012;43:104-13.

23. Suna HE, Mahmut Ö. The Achivement Gap between Turkish Schools and Realtionship between Achivement and Socioeconomic Status in Turkey. J Measurement and Evalu Education and Psychol 2021;12:54-70.

24. Stad FE, Van Heijningen CJ, Wiedl KH, Resing WC. Predicting school achievement: differential effects of dynamic testing measures and cognitive flexibility for math performance. Learn Individ Differ 2018;67:117-2

25. Majidpoor Tehrani L, Aftab R. The mediating role of cognitive emotion regulation strategies and worry in the relationship between resilience and anxiety of being infected by COVID-19. J Clin Psychol 2021;13:75-86.

26. Demirci OO, Güneri E. The Effects of Cognitive Flexibility on Cognitive Emotional Regulation. Uludağ University Faculty of Arts and Sci J Social Sci 2020;21:651-84.

27. Zlomke KR, Hahn KS. Cognitive emotion regulation strategies: Gender differences and associations to worry. Pers Individ Differ. 2010;48:408-13. 
28. Tatlı-Harmancı ÖGS, Güngör-Aytar FA. The Review The Scales Developed or Adapted in Turkey Related to Emotion Regulation. J Pearson Soc Sci Humanities 2021;6:171-85.

29. AsıCı E, Ikiz F. A Pathway to Happiness: Cognitive Flexibility. Mehmet Akif Ersoy J Educ Faculty 2015;1:191-211.

30. Stevens AD. Social problem-solving and cognitive flexibility: Relations to social skills and problem behavior of at-risk young children: Seattle Pacific University; 2009.

31. Öztürk S. Cognitive Flexibility and Emotional Autonomy in Adolescents: The Mediating Role of Cognitive Emotion Regulation Strategies. Master's Thesis, Cukurova Institute Soc Sci. 2019.

32. Aery A. Cognitive Emotion Regulation and Resilience: Adler University; 2019.

33. Salehi $A$. The role of cognitive emotion regulation strategies in the prediction of depression. Knowledge \& Research Appl Psychol 2017;16:108-17.
34. Rodríguez-Menchón $M$, Orgilés $M$, Fernández-Martínez I, Espada JP, Morales A. Rumination, Catastrophizing, and Other-Blame: The Cognitive-Emotional Regulation Strategies Involved in Anxiety-Related Life Interference in Anxious Children. Child Psychiatry Hum Dev 2021;52:63-76.

35. Goetter EM. An empirical investigation of depressive rumination: implications for cognitive flexibility, problem solving and depression. 2010.

36. Gülüm IV, Dağ i. The Turkish Adaptation, Validity and Reliability Study of the Repetitive Thinking Questionnaire and the Cognitive Flexibility Inventory. Journal Anatol. Psych. 2012;13.

37. Bedel A, Ulubey E. The Role of Cognitive Flexibility on Explanation Adolescent's Coping Strategies. Electronic J Soc Sci. 2015;14:291-300.

38. Pope SM, Fagot J, Meguerditchian A, Washburn DA, Hopkins WD. Enhanced cognitive flexibility in the seminomadic Himba. J Cross Cult Psychol 2019;50:47-62. 